\title{
AHP as Multi-criteria Decision Making Technique, Empirical Study in Cooperative Learning at Gulf University
}

\author{
Dr. Hussain Sinjar Alsamaray \\ Associate professor, administrative Science Dept., College of Administrative \\ \& Finance Science, Gulf University, Kingdom of Bahrain
}

doi: 10.19044/esj.2017.v13n13p272 URL:http://dx.doi.org/10.19044/esj.2017.v13n13p272

\begin{abstract}
Employment of the Analytic Hierarchy Process (AHP) to assess the contributions of management student team members is described. The students perform this assessment as well as the subject constrictor. The assessments are correlated with the individual team role-assignments to making a final determine of the contributions of the individual to the team effort. Using this evaluation technique appears to provide candidate student peer input for evaluations. The results demonstrated that the student ranking is more likely influenced by the relative importance of teaming, computering skills and management and by sub-criteria, communication, innovation, determination and cooperation. The study sheds importance insight into an area of multi-criteria decision making and Analytical Hierarchy Process (AHP).
\end{abstract}

Keywords: AHP, Multi-criteria decision making and pairwise comparisons matrix

\section{Introduction}

Employments of the Analytic Hierarchy Process (AHP) to assess the contributions of human resources management student team members are described. AHP can be characterized as a multi-criteria decision technique in which qualitative factors are of prime of importance. A model of the problem (teaming contribution) is developed using a hierarchical representation. At the top of the hierarchy is the overall goal or prime objective one is seeking to fulfill. The succeeding lower levels then represent the progressive decomposition of the problem and represent the criteria and sub-criteria. However, this depends on how is complex the decision problem under consideration. The individual team members complete pair-wise comparisons of all entries in each level relative to each of the entries in the next higher 
level of the hierarchy. The comparison of these judgments shows the relative priority of the entities at the lowest level relative to achieving the top objective.

A description of the AHP for the team within a Operation Research group class is described. We try to use (AHP) technique because: first the lack of success with traditional student questionnaires methods to assess team performance in spite of it is fully description, followed by description of what appears to be more meaningful results when AHP is used. Second, several complicating factors associated with this experiment, some tentative conclusions and a recommendation for continued investigation of the use of AHP for student evaluation.

\section{The Analytic Hierarchy Process (AHP) an introduction}

This section provides an introduction of AHP with emphasize on the presentation of the general methodology. No attempt is made to prove the mathematical foundations for AHP. (Saaty, T. 1980), (Saaty, 1990 )

The Analytic Hierarchy Process (AHP) was developed by Thomas Saaty in the Eightieth of the last Century and has been sine then extensively used in decision making for complex situation, it is suitable where people work together to make decision when human perception, judgment and consequences have a long term repercussion (Bhushan, 2004)

This technique is especially suited for application to project evaluation in which qualitative factors dominated. However, it can be characterized as multi-criteria decision making that can combine qualitative and quantitative factors in the overall evaluation of alternatives.

Four steps are used to solve a problem with an AHP methodology, the application by decomposed into hierarchy of criteria so as to be more easily and simply analyzed and compared in an independent situation (figure 1). The decision maker, after constructed the problem in a hierarchy way can systematically assess the alternatives by doing pair-wise comparisons for each of the chosen criteria. This comparison may use data from alternatives or human judgments as a way to input information (Saaty, 2008) 


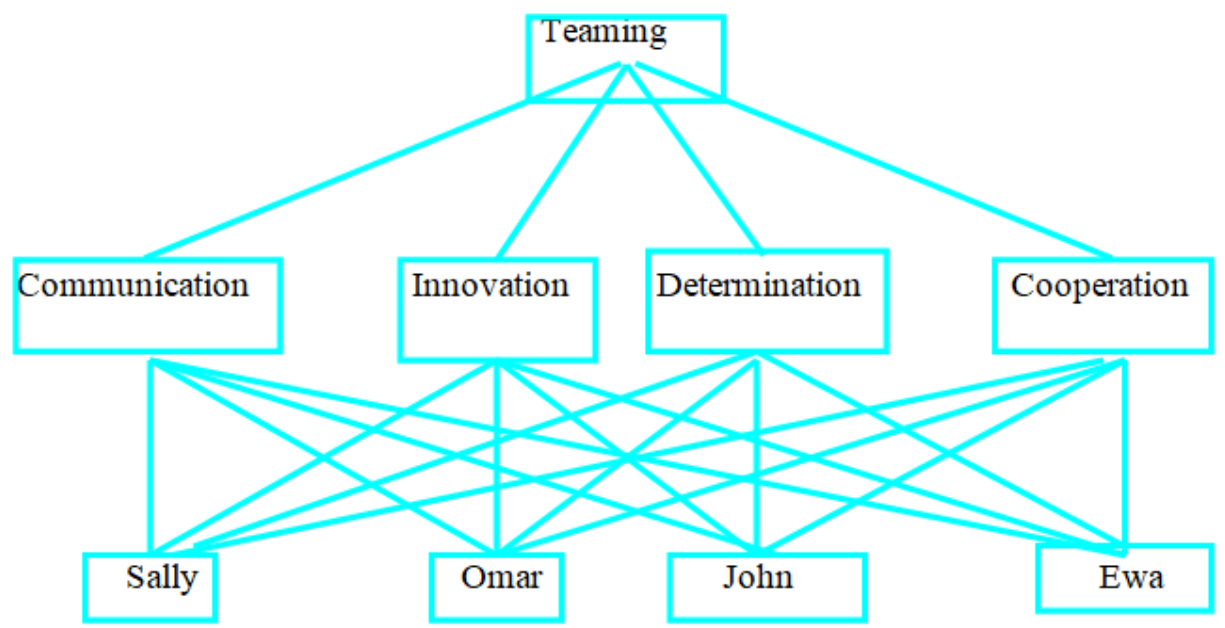

Figure (1) Example of AHP for Teaming

1- Build a decision "hierarchy" by breaking the general problem into individual criteria.

2- Gather relational data for the decision criteria and alternatives and encode these data using the AHP relational scale.

3- Estimate the relative priorities (weights) of the decision criteria and alternatives. By using (AHP software (Expert Choice), (Winston, 1989), a PC-spreadsheet (Hipre software) or expert choice software (Saaty, 2005).

4- Perform a composition of priorities for the criteria which gives the rank of the alternatives.

\section{Step 1.}

It is very essential to start developing the hierarchical representation of the problem. At the top of the hierarchy is the overall objective (goal) while the decision alternatives are at the bottom. Between the top and bottom levels are the relevant attributes or criteria of the decision problem, such as the selection criteria, sub-criteria and the various 'actors' (individuals, agencies, organizations and .....). it will provide significant input in the decision process as far as it is appropriate,. The number level of levels in the hierarchy depends on the complexity of the problem under consideration.

\section{Step 2.}

At this step we need to gather data to comparing the alternatives. This requires decision maker to make pair-wise comparisons of criteria at each level relative to each activity at the next adjacent higher level in the hierarchy.

In AHP a relational scale of numbers from 1 to 9 is used to systematically assign preferences. When comparing two attributes (or 
alternatives) $\mathrm{A}$ and $\mathrm{B}$, with respect to GOAL in a higher level, the following numerical relational scale is used (Saaty, 2005).

\begin{tabular}{|c|c|c|}
\hline & Definition & Explanation \\
\hline 3 & Equal importance & Two factors contribute equally to the objective \\
\hline 5 & Much more important & $\begin{array}{r}\text { Experience and Judgment slightly favor one } \\
\text { over the other. }\end{array}$ \\
\hline 7 & Very much more important & $\begin{array}{c}\text { Experience and Judgment very strongly favor } \\
\text { over the other. } \\
\text { one over the other. Its importance is } \\
\text { demonstrated in practice }\end{array}$ \\
\hline 9 & Absolutely more important & $\begin{array}{c}\text { The evidence favoring one over the other is of } \\
\text { the highest possible validity }\end{array}$ \\
\hline $2,4,6,8$ & Intermediate values & $\begin{array}{c}\text { When compromise is needed for finer } \\
\text { resolution }\end{array}$ \\
\hline
\end{tabular}

And we get reciprocal vales for the $(3,5,7$, and 9$)$ as follow:

1/3- B has slightly more importance than A with respect to Goal.

1/5- B has more importance than A with respect to Goal.

1/7- B has a lot more importance than A with respect to Goal.

1/9- B totally dominates A with respect to Goal.

AHP uses to determine the priority of each factor; this determination is taken into account the relativeness of any factor to the overall goal of the problem of interest. The decision maker creates a model of the problem by developing a hierarchical decomposition representation. As we mentioned earlier, at the top of the hierarchy is the overall goal or prime objective one is seeking to achieve. The succeeding lower levels represent the progressive decomposition of the problem. The decision maker completes pair-wise comparisons of all the criteria in each level relative to each of the problem criteria in the adjunct higher level of the hierarchy. The composition of these elements shows the relative priority of criteria in the lowest level (usually alternatives) relative to achieving the top-most objective. Many example application of AHP can be found in the literature (Saaty, 1980), (Saaty, 1990), (Winston, 1989), (7), (Dyer \& Forman), (Saaty, 2005) and (Haas \& Meixner, 2009).

\section{Step3}

Utilizing the pair-wise comparison of step 2 an eigenvalue method (mathematical approach) used by AHP -see (Saaty) and (Hipre software) is used to determine the relative priority of each attribute to each attribute level up in the hierarchy. Transferring the comparisons, which are most of the times empirical into numeric values that are further processed and compared? The main constrictive contribution of the AHP technique is the capability of converting empirical data into mathematical models when 
contrasted to other comparing technique (Vargas 2010). In addition a “consistency ratio" is calculated and displayed. According to Saaty (1980) small consistency, ratio (less than 0.1 is suggested rule-of thumb) does not drastically affect the ratings. The method of pairwise comparisons is systematic and comprehensive. One might want to repeat a set of pairwise comparison if the consistency ratio is alarmingly high. In spite of the decision maker has the option of redoing the comparison matrix if desired to improve the consistency.

\section{Step4}

In this step, after all comparisons have been made, and the relative weights between each one of criteria to be evaluated have been found, the numerical probability of each alternative is calculated. The probability determines the likelihood that the alternative has to achieve the expected goal. The high the probability, the better chances the alternative has to satisfy the final goal. The priorities (or weight) of the lowest level alternatives relative to the top objective are determined and displayed.

AHP facilitates a comprehensive and logical analysis of problems for which considerable uncertainty exists. In fact, the power of AHP (and to a large degree is uniqueness) is the ability to consider qualitative goal and attributes within its framework.

Generally speaking, the mathematical calculation involved in the AHP may seem simple at first, but if dealing with more complex scenario, the calculations become more complicated.

\section{Objectives of the Study}

This study aims to achieve the followings:

[a] provide an introduction to AHP with an emphasis on the presentation of the general methodology.

[b] Use AHP as multi-criteria decision making technique that can combine qualitative and quantitative factors.

[c] Use AHP as a tool of cooperative learning.

[d] Discriminate among students contribution in term work.

\section{Hypotheses of the Study} examined:

To meet the objective of study, the following hypotheses are

$\mathrm{H}_{01}$ : The students contributions are not significantly different.

$\mathrm{H}_{02}$ : Students cannot discriminated significantly in terms of criterion

(i.e., communication, innovation, determination and cooperative)

\section{AHP Use in the Operation Research Course}


The AHP steps described above can be best understood through an example application. In the Second semester of academic year 2015/2016 the instructor taught Operation Research for management course at Gulf University. One of the modules has been used is "Analytical Hierarchy Proses" (AHP), the operation research course has two tasks (Assignment and case study project) activities, it had been decided that both activities would be assigned as students team projects. Furthermore, it was decided that both activities would be spent with students on the use of AHP technique for decision analysis.

Approximately one week was allocated to explain Analytic Hierarchy Process and its used in cooperative learning, by using some examples, starting with the development of a "Code of cooperative" for team work and ending with material concerned with tools that could be used for the conduction of business project (e.g. team roles, brainstorming, affinity diagrams, normative group techniques, etc.) The students were asked to rate each attitudes of the teaming using subjective assessment. We need to mention here, people are limited in their ability to comprehend and evaluate extreme attitudes, highly unlikely events are either ignored or over weighted, and the difference between high and low priority is either neglected or exaggerated The results were quite discouraging to the instructor in that all of the students essentially rated everyone equal. This was in sharp contrast to the periodic informal students input; the instructor was receiving concerning students team. After this experience the instructor decided to try a different approach for student-to-students evaluation with assistant of EXPERT CHOICE to use the AHP technique.

To fairly evaluate students work without biasing, the instructor determining three underling aspects that should students evaluate according to them such as Teaming, Computer skills and Management. This experiment was achieved by two stages, the first one assigned to consider Teaming attribute which takes the most time of the work to let students understand the methodology and mathematical calculation while, the second stage to fulfill the two other attributes (computer skill \& management)

\section{First Stage}

The first stage started after the team of students understand the methodology of the AHP technique and have been agreed on the hierarchal representative of the problem. They completed first activity, each student utilized the hierarchy displayed in Figure (2)-fictitious names- the students were asked to do the pairwise comparisons to rank each member of the team relative to the parameter of concern. However, the method has been used to evaluate individual student on each four criterion, Communication, Innovation, Determination and Cooperation as in Figure (2). 


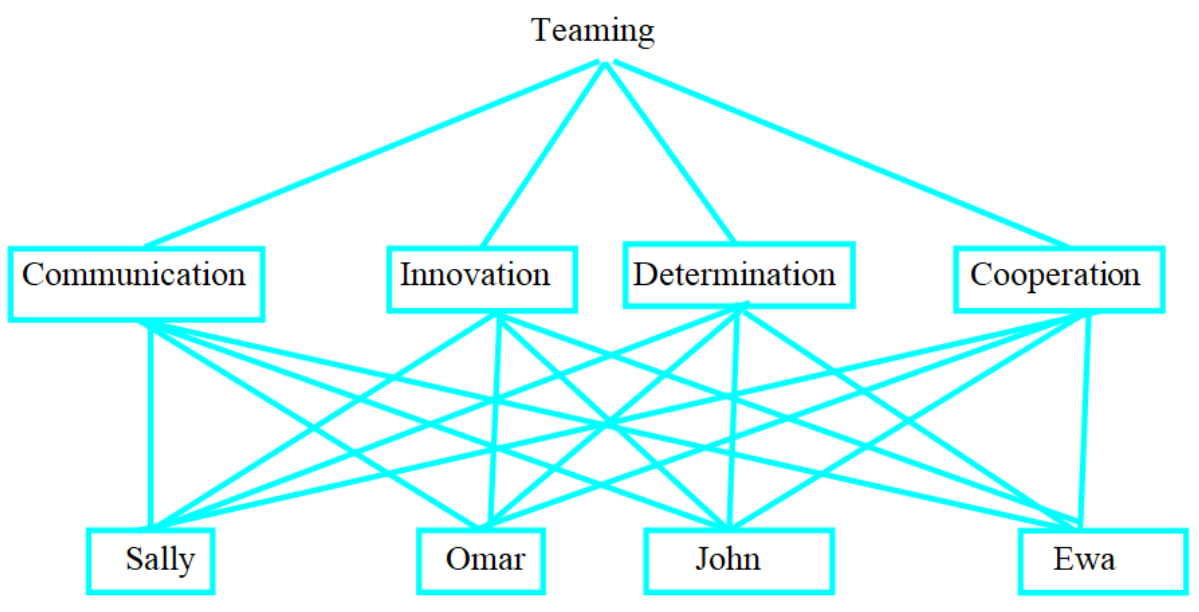

Figure (2) Priority of Teaming

The instructor and the individual student worked together to do the student pairwise comparisons. The students did all of comparisons for the teaming sub-hierarchy Figure (2). The instructor provides the students with feedback only on their degree of consistency. The students were allowed, but not required, to change only ratings if the inconsistency of their comparisons were significantly high. An example of the AHP ranking of a fictitious team is presented in Table (1).

\section{Focus: Teaming}

Communication Innovation Determination Cooperation

Communication
Innovation
Determination
Cooperation $\left(\begin{array}{llll}1 & 3 & 2 & 1 / 2 \\ 1 / 3 & 1 & 2 & 4 \\ 1 / 2 & 1 / 2 & 1 & 2 \\ 5 & 1 / 4 & 1 / 2\end{array}\right)$

Table 1 - Comparison Matrix for Teaming Criteria.

In order to find the relative weights to each criterion, it is necessary to normalize the above comparison Matrix by dividing each table value by the total the total column (Table 2). We use priority vector or Eigenvector calculation to determine the contribution of each criterion to the overall goal. The Eigenvector shows the relative weights between each criterion by calculating the arithmetic average of all criteria. So that, we can observe that the sum of all values from the vector is always equal to one 


\begin{tabular}{|c|c|c|c|c|r|}
\hline TEAMING & Communication & Innovation & Determination & Cooperation & Eigenvector \\
\hline Communication & 0.146 & 0.631 & 0.363 & 0.277 & 0.29 \\
\hline Innovation & 0.048 & 0.210 & 0.363 & 0.555 & 0.29 \\
\hline Determination & 0.073 & 0.105 & 0.181 & 0.277 & 0.17 \\
\hline Cooperation & 0.731 & 0.052 & 0.090 & 0.138 & 0.25 \\
\hline
\end{tabular}

Consistency Ratio $=0.03$

Table 2 - comparison Matrix for teaming criteria after Normalization

The values found in the Eigenvector have a direct physical meaning in AHP technique. They determine the weight of those criteria relative to the total result of the goal. For example, in our Team's contribution the Innovation criteria have a weight of 0.29 relative to the total goal. A positive evaluation on this attribute contributes more than a positive evaluation on the determination criterion 0.17 .

\section{Focus: Communication}

Sally Omar John Ewa

$$
\left(\begin{array}{ccccc}
\mathbf{S} & 1 & 3 & 3 & 1 / 6 \\
\mathbf{O} & 1 / 3 & 1 & 7 & 2 \\
\mathbf{J} & 1 / 3 & 2 & 1 & 1 / 5 \\
\mathbf{E} & 6 & 1 / 2 & 5 & 1
\end{array}\right)
$$

Table 3 - comparison Matrix for communication criteria

\begin{tabular}{|c|c|c|c|c|c|}
\hline Communication & Sally & Omar & John & Ewa & Eigenvector \\
\hline Sally & 0.130 & 0.461 & 0.278 & 0.050 & 0.23 \\
\hline Omar & 0.043 & 0.154 & 0.389 & 0.594 & 0.30 \\
\hline John & 0.043 & 0.307 & 0.056 & 0.056 & 0.12 \\
\hline Ewa & 0.782 & 0.077 & 0.278 & 0.278 & 0.35 \\
\hline
\end{tabular}

Table 4 - comparison Matrix for communication criteria after Normalization

\section{Focus: Innovation}

Sally Omar John Ewa

$$
\left(\begin{array}{ccccc}
\mathbf{S} & 1 & 4 & 3 & 5 \\
\mathbf{O} & 1 / 4 & 1 & 2 & 4 \\
\mathbf{J} & 1 / 3 & 1 / 2 & 1 & 2 \\
\mathbf{E} & 1 / 5 & 1 / 4 & 1 / 2 & 1
\end{array}\right)
$$

Consistency Ratio $=0.057$

Table 5 - comparison Matrix for Innovation criteria 


\begin{tabular}{|c|c|c|c|c|c|}
\hline Communication & Sally & Omar & John & Ewa & Eigenvector \\
\hline Sally & 0.121 & 0.117 & 0.333 & 0.551 & 0.280 \\
\hline Omar & 0.363 & 0.353 & 0.111 & 0.275 & 0.275 \\
\hline John & 0.484 & 0.353 & 0.111 & 0.034 & 0.245 \\
\hline Ewa & 0.030 & 0.176 & 0.444 & 0.139 & 0.200 \\
\hline
\end{tabular}

Table 6 - comparison Matrix for Innovation criteria after Normalization

Focus: Determination

Sally Omar John Ewa

$\left(\begin{array}{ccccc}\mathbf{S} & 1 & 7 & 3 & 1 \\ \mathbf{O} & 1 / 7 & 1 & 4 & 1 / 5 \\ \mathbf{J} & 1 / 3 & 1 / 4 & 1 & 5 \\ \mathbf{E} & 1 & 5 & 1 / 5 & 1\end{array}\right)$

Consistency Ratio $=0.006$

Table 7 - comparison Matrix for determination criteria

\begin{tabular}{|c|c|c|c|c|c|}
\hline Communication & Sally & Omar & John & Ewa & Eigenvector \\
\hline Sally & 0.403 & 0.528 & 0.365 & 0.138 & 0.36 \\
\hline Omar & 0.057 & 0.075 & 0.487 & 0.028 & 0.16 \\
\hline John & 0.134 & 0.019 & 0.121 & 0.694 & 0.24 \\
\hline Ewa & 0.403 & 0.377 & 0.024 & 0.139 & 0.24 \\
\hline
\end{tabular}

Table 8 - comparison Matrix for determination criteria after Normalization

Focus: Cooperation

\begin{tabular}{|c|c|c|c|c|c|c|}
\hline \multirow[t]{5}{*}{ Sally } & \multirow[t]{5}{*}{ Omar } & John & Ewa & & orities & \\
\hline & & 1 & 5 & 8 & 1 & 0.396 \\
\hline & & $\begin{array}{ll}\text { D } & 1 / 5\end{array}$ & 1 & 3 & $1 / 3$ & $=0.122$ \\
\hline & & $1 / 8$ & $1 / 3$ & 1 & 8 & 0.114 \\
\hline & & 1 & 3 & $1 / 8$ & 1 & 0.367 \\
\hline
\end{tabular}

Table 9 - comparison Matrix for cooperation criteria

\begin{tabular}{|c|c|c|c|c|c|}
\hline Communication & Sally & Omar & John & Ewa & Eigenvector \\
\hline Sally & 0.430 & 0.535 & 0.659 & 0.097 & 0.43 \\
\hline Omar & 0.086 & 0.107 & 0.247 & 0.024 & 0.12 \\
\hline John & 0.053 & 0.035 & 0082 & 0.780 & 0.24 \\
\hline Ewa & 0.430 & 0.321 & 0.010 & 0.097 & 0.21 \\
\hline
\end{tabular}

Table 10 - comparison Matrix for determination criteria after Normalization 
Sally
Oma
r
John
Ewa

$\begin{array}{crr}\begin{array}{c}\text { Communicatio } \\ \text { n }\end{array} & \begin{array}{r}\text { Innovatio } \\ \mathrm{n}\end{array} & \begin{array}{r}\text { Determinatio } \\ \mathrm{n}\end{array} \\ 0.23 & 0.28 & 0.36 \\ 0.12 & 0.28 & 0.16 \\ 0.35 & 0.24 & 0.24 \\ & 0.20 & 0.24\end{array}$

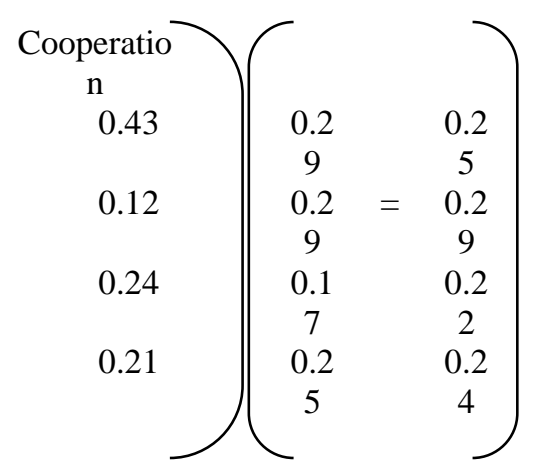

Table 11- Final Priorities for Teaming Criteria

AHP Team Assessment

Overall Priorities for teaming are as follow:

0.25

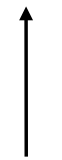

Sally
0.29

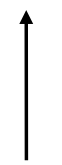

OMAR
0.22

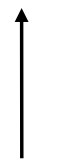

John
0.24

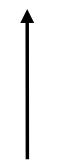

Ewa

These priorities explain the relative importance of teaming attributes of the four students. This relative importance depicts in Table (11).These priorities indicate that Sally gets the highest $(0.29)$ ranking whereas John gets the lowest (0.22) ranking.

\section{Ranking of Priorities \& Consistency Ratio}

One of the most positive characteristics of the (AHP) its ability to measure the degree of Consistency provisions of the decision-maker, homogeneity or consistency in judgments of great importance because it is not reasonable to take certain decisions that are important based on the weak provisions. Homogeneity comes as results of error in the hierarchical structure of the decision problem or from lack of information, mental lapse or missed priestly clerical error (Alsamaray, 1997). It bears the relationship between the homogeneity of the verdicts and accuracy of some of the discussion where minute verdicts are usually homogeneous, but not necessary homogeneity judgments lead to the provisions of true and accurate. Therefore, the homogeneity of the verdicts is necessary but not sufficient for good decision making. The best way to get provisions homogeneous is doing a measurement process for many times and find the average, which is the closest of all the numbers in the measurement series to the homogeneity and stability. 
Consider Eigenvector $A X=\left(\lambda_{\max } X \quad\right.$ where $)$

- $\quad \mathrm{A}$ is the comparison matrix of size $\mathrm{n} \times \mathrm{n}$, for $\mathrm{n}$ criteria

- $\mathrm{X}$ is the Eigenvector of size $\mathrm{n} \times 1$

- $\lambda_{\max }$ is the Eigenvalue, $\lambda_{\max } € ® \geq n$

1- To find the rank of priorities, the Eigenvector $\mathrm{X}$ :

Iterate

Take the squared power of matrix A, i.e.,

$A^{2}=A \cdot A$

$\mathrm{A}^{2}=\mathrm{A} . \mathrm{A}$

Find the row sums of $\mathrm{A}^{2}$ and normalize this array to find E0, until differences between successive row sums is less than a pre-specified value

Set $\mathrm{A}=\mathrm{A}^{2}$

Main:

1- Take the squared power of matrix A, i.e., $\mathrm{A}^{2}=\mathrm{A} x \mathrm{~A}$

2- Find the row sums of $\mathrm{A}^{2}$ and normalize this array to find E1

3- Find D = E1 - E0

4- If the values of $D$ are close to zero, then $X=E 1$, stop. Else set $A:=A^{2}$, Set E0: = E1 go to step

Using (AHP) does not mean to reach full homogeneity but to know what is the amount of non-acceptable homogeneity in clarifying our choices?. AHP technique provides method called consistency Ratio. If the percentage of non-uniformity equal to 0.10 or less is acceptable. If they are larger than this figure must be doing research and investigate by experiment to know the main reason for behind the lack of homogeneity. If what has been the various causes leading to the exclusion of heterogeneity can sometimes accept a percentage of non-uniformity even if a little bigger than 0.1. The following steps can be used to calculate the percentage of nonhomogeneity of the matrix comparisons which have previously been discussed in the preceding paragraph

We need to look for any data inconsistencies. The objective is to get enough information to decide whether the decision makers have been consistent in their choices (Teknomo, 2006). For example, if the decision makers affirm that the innovation criteria are more important than cooperation criteria and that cooperation criteria are more important than the determination criteria, it would be inconsistent to affirm that the determination criteria are more important than the innovation criteria( if $\mathrm{A} \geq$ $\mathrm{B}$ and $\mathrm{B} \geq \mathrm{C}$ it would be inconsistent to say that $\mathrm{A} \leq \mathrm{C}$ ).

1- .Multiply each column in the matrix of bilateral comparisons, the relative priority of each sector and then collect rows values for a set of weights, as follows 
Focus: Teaming

\begin{tabular}{|c|c|c|c|c|c|}
\hline \multicolumn{2}{|c|}{ Communication } & Innovation & Determination & Cooperation & \\
\hline Communication & 1 & 1 & 4 & 0,309 & 1.255 \\
\hline Innovation & 1 & 1 & $1 / 2$ & 0221 & 0.8925 \\
\hline Determination & $1 / 4$ & $1 / 2$ & $\begin{array}{c}x_{1} \\
1\end{array}$ & $\begin{array}{c}= \\
0.085\end{array}$ & d.350 \\
\hline Cooperation & 1 & 2 & 5 & 0.385 & 1.561 \\
\hline
\end{tabular}

Table

$\mathrm{C}=0.309 * 1+0.221 * 1+0.085 * 4+0.385 * 1=1.255$

$\mathrm{I}=0.309 * 1+0.221 * 1+0.085 * 2+0.385 * 1 / 2=0.8925$

$\mathrm{D}=0.309 * 1 / 4+0.221 * 1 / 2+0.085 * 1+0.385 * 1 / 5=0.35$

$\mathrm{CO}=0.309 * 1+0.221 * 2+0.085 * 5+0.385 * 1=1.561$

2- .Dividing the sum of each row on the relative importance of that row

$1.255 / 0.309=4.061$

$0.8925 / 0.221=4.038$

$0.35 / 0.085=4.117$

$1.561 / 0.385=4.054$

3- .Find values rate in the second step and the resulting called $\lambda_{\max }$ $\lambda_{\max }=4.061+4.038+4.117+4.054 / 4=4.068$

4- Find homogeneity index (C1) Consistency Index according to the following equation

$$
\mathrm{CI}=\frac{\lambda \max -\mathrm{n}}{\mathrm{N}-1}
$$

When $\mathrm{n}=$ the number of items that have been compared and equal in our example 4

$$
\begin{gathered}
\mathrm{CI}=\frac{(4.068-4}{3} \\
\mathrm{CI}=\frac{0.068}{3}=0.027
\end{gathered}
$$

Find Consistency Ratio (CR) according to the following equation

$\mathrm{R} 1=$ random index

$$
\mathrm{CR}=\frac{\mathrm{CI}}{\mathrm{RI}} \ldots \ldots
$$

The index is a random homogeneity index for a randomized, matrices of size n comparisons and bilateral as follows (Dyer \& Forman, 1991) 


\begin{tabular}{|c|c|}
\hline $\mathrm{N}$ & $\mathrm{R} 1$ \\
\hline 2 & 0.00 \\
\hline 3 & 0.58 \\
\hline 4 & 0.90 \\
\hline 5 & 1.12 \\
\hline 6 & 1.24 \\
\hline 7 & 1.32 \\
\hline 8 & 1.41 \\
\hline
\end{tabular}

The indiscriminate index for our example is $\mathrm{R} 1=0.90$ and that the percentage of non-homogeneity $\mathrm{CR}=0.027 / 0.9=0.03$ and $\leq 0.10$. The provisions of estimates and the results of the decision-maker in the appreciation rate of 0.03 , less than 0.1 , so the evaluations are highly acceptable.

Students” priority were somewhat variable but in aggregate coincided with the instructor opinion of individual student performance. After, the students succeeded in doing all of comparisons for the teaming sub-hierarchy Figure (2) which result in high confidence to them.

\section{Second Stage}

Having finished the determination of teaming in first stage and the students have good experience of doing pairwise comparison matrices they are asked to do complete project assessment hierarchy as in figure (3). The method used consisted to evaluate each individual student on other two criteria - Computer skills and Management.

We have the following matrices

Computering Communication Innovation Determination

Cooperation

$\begin{array}{lllll}\text { Communication } & 1 & 3 & 2 & 4 \\ \text { Innovation } & 1 / 3 & 1 & 4 & 5 \\ \text { Determination } & 1 / 5 & 1 / 4 & 1 & 2 \\ \text { Cooperation } & 1 / 4 & 1 / 5 & 1 / 2 & 1\end{array}$

Table 12 - comparison Matrix for computer skills criteria

\begin{tabular}{|lccccccc|}
\hline \multicolumn{2}{|c}{ Normalized } & C & I & \multicolumn{2}{c|}{ D } & Co & Eigenvector \\
\hline C & 0.48 & 0.6741 & 0.2666 & 0.3333 & 0.44 & & \\
I & 0.16 & 0.2247 & 0.5333 & 0.4167 & 0.33 & & \\
D & 0.24 & 0.0561 & 0.1333 & 0.1667 & 0.15 & & \\
Co & 0.12 & 0.0449 & 0.0666 & 0.0833 & 0.08 & & \\
\hline
\end{tabular}

Table 13 - comparison Matrix for computering skills criteria after Normalization 


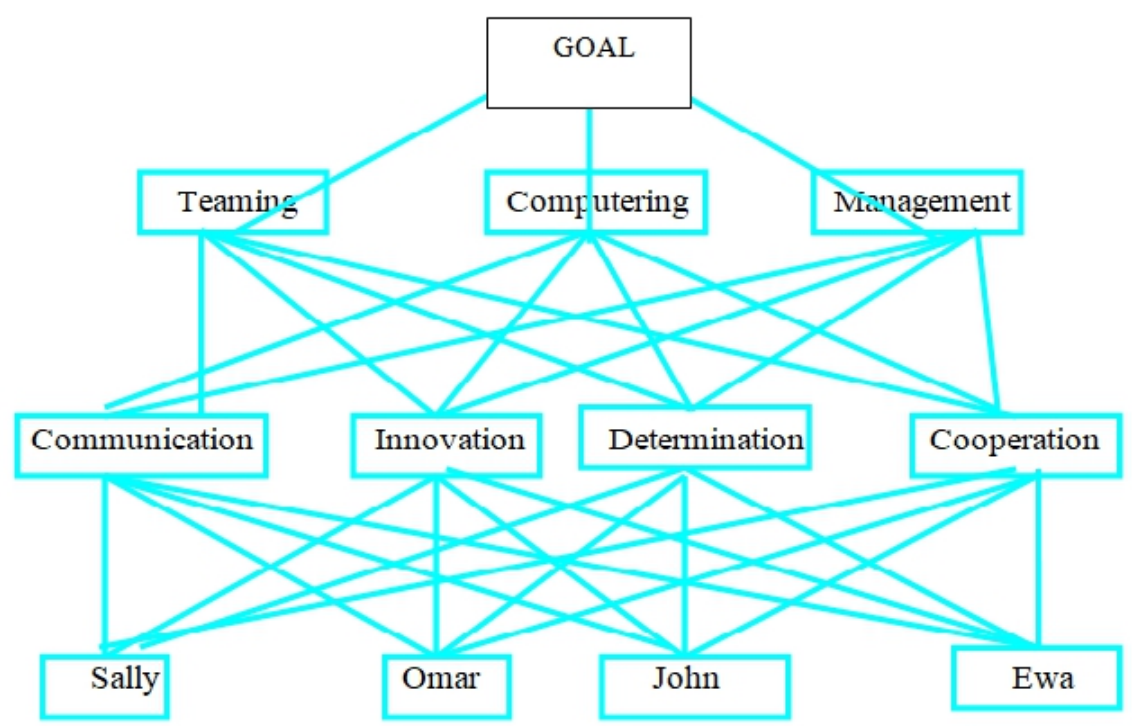

Figure (3) Complete Project Assessment Hierarchy

\begin{tabular}{lcccc|}
$\begin{array}{llccl}\text { Management } \\
\text { Cooperation }\end{array}$ & Communication & Innovation & Determination & \\
\cline { 1 - 3 } Communication & 1 & $1 / 3$ & 2 & 5 \\
Innovation & 3 & 1 & 3 & $1 / 4$ \\
Determination & $1 / 2$ & $1 / 3$ & 1 & 3 \\
Cooperation & $1 / 5$ & 4 & $1 / 3$ & 1 \\
Column Total & 4.7 & 5.6666 & 6.3333 & 9.25 \\
& Table 14 - comparison Matrix for Management criteria &
\end{tabular}

Normalized Commutation Innovation Determination Cooperation Eigenvector

\begin{tabular}{|llllll|}
\hline C & 0.2127 & 0.0588 & 0.3179 & 0.5405 & 0.27 \\
I & 0.6382 & 0.1764 & 0.4736 & 0.0270 & 0.33 \\
D & 0.1063 & 0.0588 & 0.1578 & 0.3250 & 0.17 \\
Co & 0.0425 & 0.7085 & 0.0526 & 0.1081 & 0.23 \\
\hline
\end{tabular}

Table 15 - comparison Matrix Management criteria after Normalization

Of particular interest to this study is to find out whether the students can be correctly classified as the same straight-line as in Teaming. In other words, is the student with high relative importance in one criterion should be gotten the high relative in other criteria as well? Table (16) and figure (4) illustrates that the student significantly vary in tackling different criteria. However, its' clearly appeared that Omar has been taken the highest priority in Computer skills whereas, he classified as in the second place in Management and third in Teaming Figure (4). 


\begin{tabular}{|c|c|c|c|}
\cline { 2 - 4 } \multicolumn{1}{c|}{} & Teaming & Computering skills & Management \\
\hline Communication & 0.29 & 0.44 & 0.23 \\
\hline Innovation & 0.29 & 0.33 & 0.29 \\
\hline Determination & 0.17 & 0.15 & 0.11 \\
\hline Cooperation & 0.25 & 0.08 & 0.37 \\
\hline
\end{tabular}

Table: 16 Relative Priorities for level two criteria

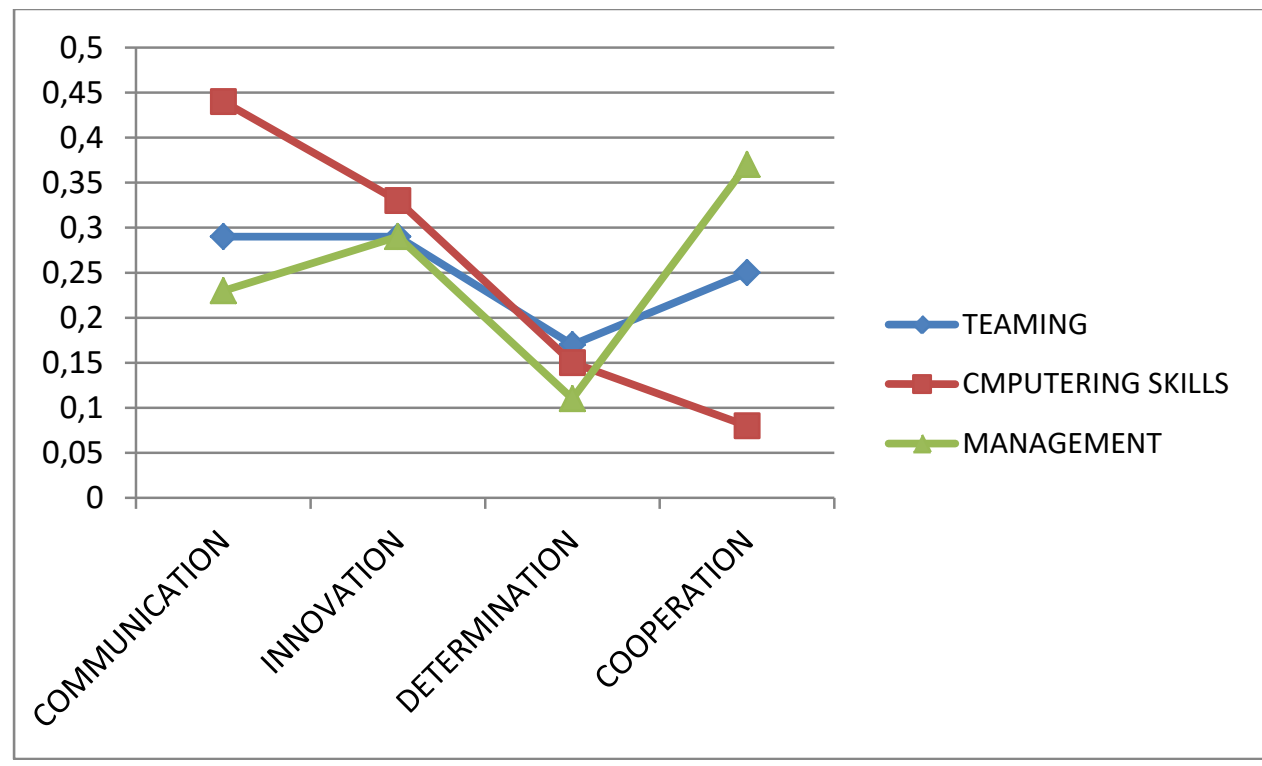

Fig. 4 Priorities of sub-criteria in third level in the hierarchy

$\left.\begin{array}{cccc}\text { Communication } & \text { Teaming } & \begin{array}{c}\text { Computer } \\ \text { Skills }\end{array} & \text { Management } \\ \text { Innovation } & 0.29 & 0.44 & 0.23 \\ & 0.29 & 0.33 & 0.29 \\ \text { Determination } & 0.17 & 0.15 & 0.11 \\ \text { Cooperation } & 0.25 & 0.08 & 0.37\end{array}\right)\left(\begin{array}{c} \\ 0.57 \\ 0.26 \\ = \\ 0.17\end{array}\right)\left(\begin{array}{c} \\ \end{array}\right)\left(\begin{array}{c} \\ 0.32 \\ 0.30 \\ 0.22 \\ \end{array}\right)$

Table -17 Relative priorities for second level of the criteria

\begin{tabular}{|c|c|c|c|c|c|c|}
\hline & Communication & Innovation & Determination & Cooperation & & \\
\hline Sally & 0.23 & 0.28 & 0.36 & 0.43 & 0.32 & 0.31 \\
\hline Omar & 0.30 & 0.28 & 0.16 & 0.12 & 0.30 & 0.23 \\
\hline John & 0.12 & 0.24 & 0.24 & 0.24 & 0.16 & 0.20 \\
\hline Ewa & 0.35 & 0.20 & 0.24 & 0.21 & 0.22 & 0.26 \\
\hline
\end{tabular}

Table -18 Overall priorities for the students 


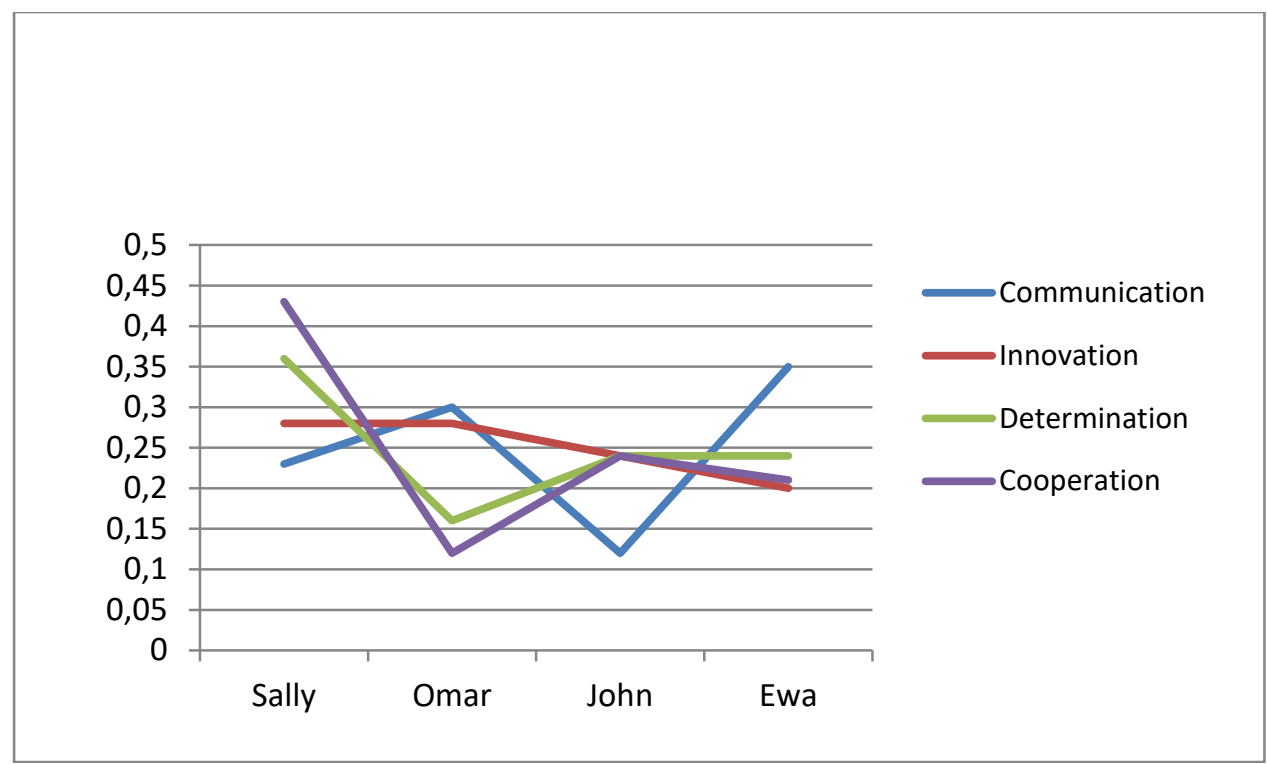

Fig. 5 Overall priorities of the Students

We can find the overall priorities to each individual student after completed all pairwise comparisons to the low level of hierarchy. The low level consists of four criteria, Communication, Innovation, Determination and Cooperation as illustrated above in Figure (3). The results appear in table (18) indicate that the perceived relative importance of criteria determinate vary from one student to another. This finding and the above reveals that, there are a number of attributes that are of particular importance to students to decide their contribution regardless of past doing. Such students' attributes mainly pertain to personnel differences.

Table (18) illustrate that Sally takes the highest priority [0.31], Ewa has gotten [0.26], while Omar gets [0.23] and John gets the lower priority [0.20]. So that, if we assume that Sally deserves excellent grade[90], however, this will help us to assign grade to other individual students as, [84, 74 and 65] to Ewa, Omer and John respectively.

\section{Conclusion}

This is an interesting exercise in many ways. The use of cooperative learning was a good educational experience, although at times painful for both students and instructor. The main conclusions are:-

1- The use of AHP technique is useful in that it provided a structured approach for problem formulation by seeking students' opinions.

2- The AHP technique may have been sufficient motivation for some students to be concerned with teaming performance. 
3- Another consideration is that the use of AHP without thoroughly exploring how the technique is worked (the instructor did give 6 pages explanation and rules for using the (AHP), (Expert Choice), (Winston 1989) and (Hipre software) as reference for this technique) may have inhibited the students from "gaming” their evaluations.

4- The results indicate that the perceived relative importance of criteria vary from one to another. This is especially true with regard to communication [0.32], innovation [0.30], cooperation [0.22] and determination [0.16].

5- The results also reveal that the students have given different contribution to the terms considered, which reflect the differences in their (i.e., knowledge, experience, intelligence and interaction in teaming), in order of priority, Sally [0.31], Ewa [0.26], Omar [0.223] and John [0.20].

6- The study sheds importance insight into an area of multi-criteria decision making analysis and expert choice.

7- Finally, the study opened the door for further studies to enhance the learning and teaching process at high education institutes.

\section{References:}

1. Al Harbi K.M,A,S,(1999), Application of AHP in Project Management, International Journal of Project Management, 19 19-27.

2. Alsamaray, Hussain (1997), “ Toward New approach in determining Investment Decision” Al-Idary, Oman, Muscat, No.69, PP 41 - 65

3. Anderson, Sweeney and Williams, (1989), "Quantitative Methods for Business" $4^{\text {th }}$. Ed. , St Paul, West Publishing Company

4. Bhushan, N. \& Rai, K. (2004) Strategic Decision Making: Applying the Analytic Hierarchy Process., New York: Springer

5. Dyer and Forman (1991), “An Analytic Approach to Marketing Decision”, Prentice-Hall International Editions

6. Expert Choice software available from Expert Choice Inc., Pittsburgh, PA3)

7. Haas R., Meixner, O., (2009) An Illustration Guide to the AHP, Lecture Notes, Institute of Marketing \& Innovation, University of Natural Resources and http:www.boku.ac.at/mi/

8. Hipre software available from Santa Monica Software, Malibu, C.A.

9. Saaty, Thomas, L., (1980), “The Analytical Hierarchy Process”, McGraw-Hill Co., New York.

10. Saaty, Thomas, L., (1990),” How to Make a Decision: The Analytical Hierarchy Process”, European Journal of Operations Research, 48, pp 9-26. 
11. Saaty, T.L., Vargas, L. G., (2001), Models, Methods, Concepts \& Applications of the AHP, Kluwer's Academic Publishers, Boston, USA.

12. Saaty, T. (2005), Theory and Application of the Analytic Network Process: Decision Making with Benefits, Opportunities, Cost and Risks. Pittsburg: RWS Publications.

13. Saaty, T. (2008), Relative Measurement and its Generalization in Decision Making: Why Pairwise Comparisons are Central in Mathematics for the Measurement of Intangible Factors- the Analytic Hierarchy/Network Process. Madrid: Review of the Royal Spanish Academy of Science, Series A, Mathematic. Available at http://www.rac.es/ficheros/doc/00576.pdf

14. Teknomo, K (2006), Analytical Hierarchy Process (AHP) Tutorial Available at http://people. Revoledu.com/kardi/tutorial/ahp/

15. Vargas, L.G. (1990) An Overview of the Analytic Hierarchy Process and its Application. European Journal of Operation Research, 48, 2-8.

16. Vargas, L.G. (2010) Using the Analytic Hierarchy Process (AHP) to Select and Prioritize Project in a Portfolio

17. Winston, Wayne, L., (1989), “Operations Research: Applications and Algorithms”, $2{ }^{\text {nd }}$ Ed., Duxbury Press. 